\title{
Hydraulic leveling control system of harvester chassis
}

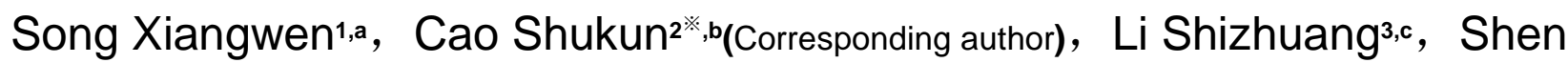

\author{
$\mathrm{HaO}^{4, \mathrm{~d}}$ \\ ${ }^{1}$ Nanxinzhuang West Road 336Jinnan, School of Mechanical Engineering, University of Jinan, \\ Jinan 250022, Shandong Province, China \\ ${ }^{2}$ Nanxinzhuang West Road 336Jinnan, School of Mechanical Engineering, University of Jinan, \\ Jinan 250022, Shandong Province, China \\ ${ }^{3}$ Nanxinzhuang West Road 336Jinnan, School of Mechanical Engineering, University of Jinan, \\ Jinan 250022, Shandong Province, China \\ ${ }^{4}$ Nanxinzhuang West Road 336Jinnan, School of Mechanical Engineering, University of Jinan, \\ Jinan 250022, Shandong Province, China \\ a751937831@qq.com b87756997@qq.com c1148660320@qq.com d354174809@qq.com
}

Key words: harvester stable;oil and gas suspension; angle error control algorithm

\begin{abstract}
Based on the research of the position error control algorithm and the angle error control algorithm, according to the specific characteristics of the harvester, the leveling control strategy of angle error control algorithm is proposed in this paper. Making leveling at both direction of X and Y, first adjust the direction of large angle. By reducing the hydraulic cylinder to reduce the center of the harvester and keep harvester stable. When lowing one side of the harvester unable to achieve leveling, then raising the other side. Finally, writing some programs of the whole leveling process.
\end{abstract}

\section{Introduction}

The existing oil and gas suspension system, the widespread use of independent oil and gas suspension system and connected hydraulic system, but in the anti-rollover performance, the connected type of oil and gas suspension can significantly improve the vehicle's anti-rollover performance, reduce the vehicle The roll angle generated when turning, so that the vehicle is more stable, and the hydraulic system is simple, so the large wheeled vehicle chassis hydraulic system and more use of connected type oil and gas suspension system. But because the traditional connected hydraulic system is not the flow control, and because we harvester front and rear bridge load is different, resulting in different pressure cylinder, resulting in different working position of the accumulator, resulting in the speed of lifting is not the same, the final body there is a tilt of the situation, or left and right roll, or roll back and forth, in short, the vehicle lift function can not be applied normally, which will harves the efficiency of harvesting, anti-rollover performance, vehicle passing and mobility to bring serious impact, so the problem seriously restricts the application of the automatic leveling function of the harvester.

\section{Design of hydraulic system for connected hydraulic system}

\section{Study on the Principle of Traditional Connected Oil and Gas Suspension}

The schematic diagram of the traditional connected type oil and gas suspension is shown in 
Fig.1:

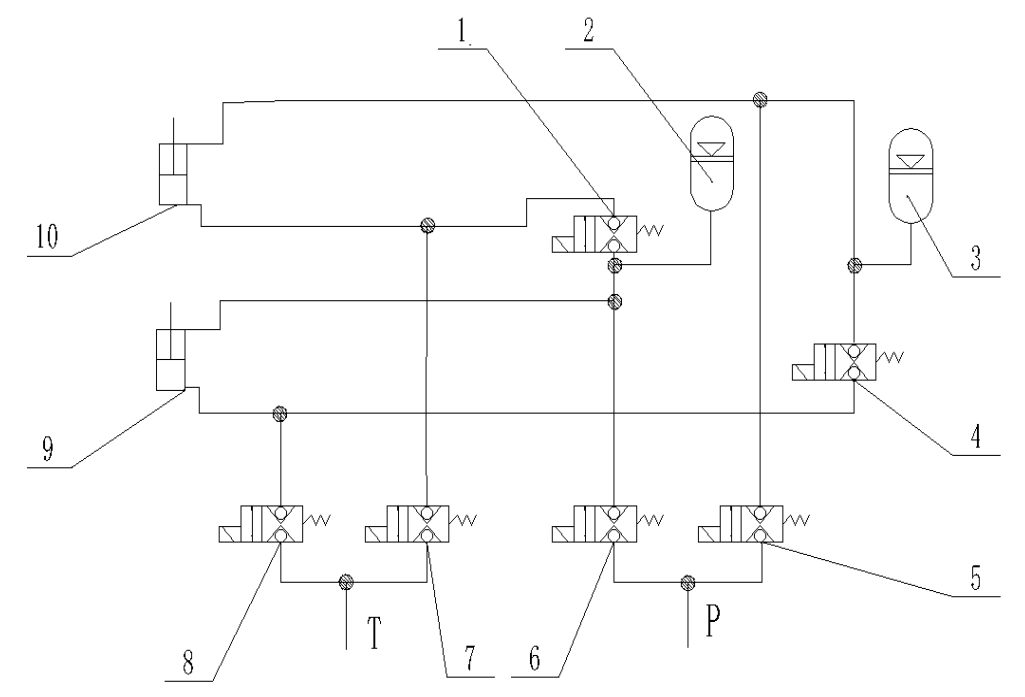

1, 4, 5, 6, 7, 8 - two-way two-way solenoid valve 2,3-accumulator 9,10- suspension cylinder

Fig.1 Hydraulic model of connecting type oil and gas suspension

Connect the type of oil and gas suspension system to X-type connected to the majority, that is, right front and left after the connection, left and right rear connection, such a corner increase, will inevitably lead diagonal reduction, faster and better finish body leveling. As shown in Figure 1 above, when the front right side is raised, the opening of the solenoid valve 6 opens, the oil enters the left rear hydraulic cylinder through the solenoid valve 6 and enters the right front through the solenoid valve 1 The hydraulic cylinder has no rod cavity, resulting in an increase in the right front hydraulic cylinder. As the right side of the increase, resulting in the right side of the rod cavity pressure, resulting in the left side of the hydraulic cylinder rod pressure will be increased, but because the left side of the hydraulic cylinder into the oil, the pressure will rise. So eventually lead to the right front side of the rise. When the front right side of the hydraulic cylinder increases, the right front side of the hydraulic cylinder has reduced the rod cavity, the pressure increases, resulting in a slight increase in the left rear hydraulic cylinder, but the overall increase in the right front. However, for the harvester, due to the huge difference between the front and rear axle load, the role of the pressure on both sides of the hydraulic cylinder on the pressure, resulting in different working position of the accumulator, resulting in the speed of lift is uncertain, resulting in the left and right side of the hydraulic lift Can not be synchronized.

\section{Constant flow, pressure tracking connected hydraulic system}

For the harvester front and rear axle bearing a huge difference caused by the left and right leveling, the one-sided hydraulic cylinder can not synchronize the lifting of the problem, the reasons for the analysis, first, because the suspension tank into the oil flow is not flow control, so that into the suspension cylinder The flow is different, this we can by adding fuel flow control valve to ensure that the flow at both ends of the same; second, can not eliminate the accumulator caused by load changes caused by the impact of oil filling, for this point, due to oil and gas suspension Flattening the various hydraulic cylinder load is different, then only in leveling, the accumulator cut off, that is, in the process of raising the accumulator will first cut off, through the control of the flow valve to extend the suspension, because there is no energy storage The impact of the flow valve can be controlled by the side of the suspension cylinder simultaneously lift. However, after leveling, due to the pressure in the accumulator and the pressure in the oil circuit is different, when re-access to the accumulator, due to the large difference in pressure, will make the hydraulic cylinder status 
changes rapidly, resulting in hydraulic cylinder jitter, In this paper, the pressure control valve is installed in the hydraulic control system. When the accumulator is cut off, the pressure in the accumulator is kept at the same pressure as the oil in the leveling process. A schematic diagram of the synchronous lift system based on constant flow is shown in Fig 2 below.

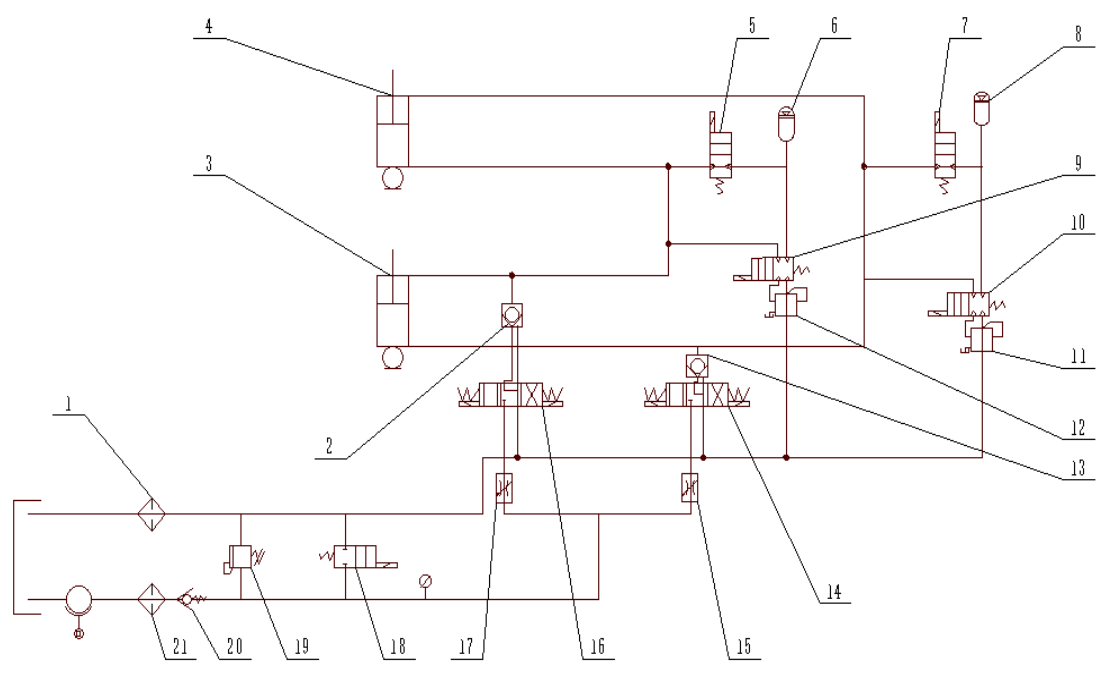

1,21-filter 2,13,2-check valve 3,4 hydraulic cylinder 5,7,18-two-way two-way electromagnetic valve 6,8-accumulator 9,10-two-way four-way electromagnetic commutation ball valve 11,12-pressure tracking valve 14,16-three four-way electromagnetic valve 15,17 -speed valve

Fig.2 Schematic diagram of a synchro-ascending system based on constant flow-connected cascade

The whole system hydraulic principle is: first turn off the solenoid valve 5,7, the accumulator and the suspension cylinder cut off, while opening the solenoid valve 9,10,14,16, high pressure oil to push the suspension cylinder, 15, 17, the flow rate of the one side suspension cylinder is the same, and the side suspension cylinder is simultaneously extended so that the harvester side is raised synchronously, and when the solenoid valves 9 and 10 are opened during the raising process, And the pressure tracking valves 11, 12 are allowed to operate so that the pressure in the accumulator can always follow the pressure in the suspension cylinder, i.e. the pressure in the accumulator is the same as the pressure in the suspension cylinder. When the solenoid valve 9, 10, 14, 16 is de-energized and the solenoid valves 5, 7 are energized, the high-pressure port is closed and the accumulator is connected to the system. At this time, Pressure equal, can achieve a smooth switch to ensure the smooth vehicle.

Fig 2 in the ordinary hydraulic control valve works: when the control port has control of oil pressure, the pressure oil to promote the piston, and then push the cone valve spool open, so that the oil P1 to P2 and P2 to P1 are connected, When the hydraulic port $\mathrm{K}$ oil pressure is zero, with the ordinary one-way valve function, the oil P1 to P2 connected, P2 to P1 is not connected.

\section{Independent control of hydraulic systems}

However, the entire hydraulic system can be connected to the hydraulic system can ensure synchronous lifting, but because the entire oil control is complex, and the pressure tracking valve is not ready-made products, the whole device can not learn from the experience, consider the harvester control needs and costs, And the project needs, the hydraulic system does not use the connected hydraulic control system, using a relatively simple independent control hydraulic system. The hydraulic system is shown in Fig. 3 below. 


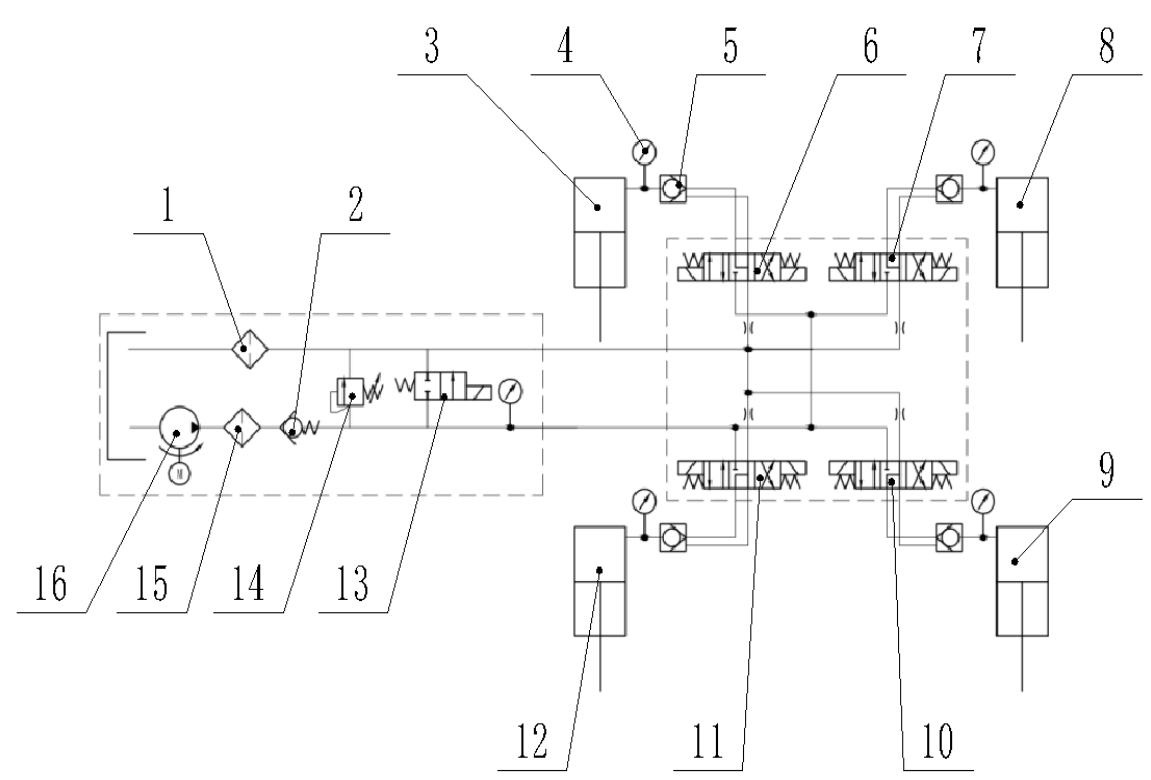

1,15-filter 2,5-check valve 3,8,9,12-hydraulic cylinder 4 pressure gauge 6,7,10,11-three-position four-way electromagnetic valve 13-two-way two-way electromagnetic valve 14 - relief valve 16 - hydraulic pump

Fig. 3 Independent control of the hydraulic control system

Hydraulic oil through the three four-way electromagnetic valve to the hydraulic cylinder without rod into the oil, and then flatten the end of the one-way valve to seal the oil in the hydraulic cylinder rodless cavity, when the hydraulic cylinder need to restore, through the body Gravity, while the pressure to the pilot port, so that one-way valve to open again, the oil reflux.

\section{Conclusions}

This chapter determines the hydraulic control system of the oil and gas suspension using the connected hydraulic control system of oil and gas suspension, and controls the single cylinder relative to the traditional single valve, and the anti-rollover effect is better. In the analysis of the traditional loader before and after the bridge load and the traditional connected type of oil and gas suspension is insufficient, the proposed speed control valve and pressure tracking valve connected hydraulic system hydraulic control system.

\section{Acknowledgements}

This work was financially supported by the Shandong Province, the major project of science and technology (item number: 2015ZDZX10001) " the development and industrialization demonstration of intelligent corn combine harvester" .and Taishan industry leading talent project special funds.

\section{References}

[1] Kyuhyun Sim, Hwayoung Lee. Effectiveness Evaluation of Hydro-pneumatic and Semi-active Cab Suspension for the Improvement of Ride Comfort of Agricultural Tractors[J]. Journal of Terramechanics,2016.Giacomin J.,Neural network simulation of an automotive shock absorber,Engineering Application Artificial Intelligence,Vo1.4,No.1 Paragon Press, 1991:59-64P. 
[2] Bauer Wolfgang, Hydropneumatic suspension system[M]. Verlag Berlin Heidelberg: springer,2011.

[3] H.G.Gibson,K.C.Elliott. Side slope stability of articulated-frame logging tractors[J].Journal of Terra mechanics, 1971(2): 65-79.

[4] Ralf.Eger,Majjad.Rachid.Rollover simulation based on a Nonlinear Model[J].SAE special publications, 1998(11): 1-7.Novak A.J,Larson C.S. Computer simulation of semi-trailer haul truck roll-over dynamics. Society of Automotive Engineers[ J]. 1990, 99(2): 491-497.

[5] Wilson, JN, Klassen, N.D. Sensor requirements for combine harvester control[J].Soeiety of Auto motive Engineers Transactions,1991,100(2):239-247. 